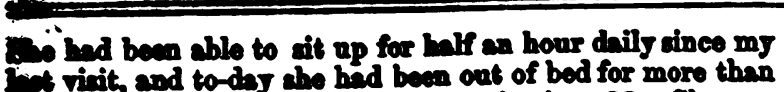
Wint vicit, and to-das she had been out of bed for more than ine Jefres's repirator. The treatment was continued.

Feb. 7th. Convalescenco was adrancing very entisfaccoily. The voice and respiration were natural, and the congh nearly gone. Percussion and auscultation gave clmost the same results as in 1850; and she was sensible of an increace of strength. Of late she lad been little in bed during the day; and this evening I found her sitting up, dresed, and engaged in the perusal of the ubiquitous Jnale Tom's Cabin.

Por the succeeding ten months, the use of cod-liver oil, with attention to diet, and careful aroidance of exposure to cold, secured to the patient a measure of health to which she had long been a stranger. During this period I only aw her incidentally, except once or twice for a threatening of bronchitis, which an expectorant mixture and a mild counter-irritant to the chest seemed to avert; but, on the SOth of Norember last, the laryngitis suddenly recurred, and with fully its former intensity, again setting at nought al my efiorts for its removal without the aid of tracheotomy; leeches to the sides of the larynx, followed by blisters; the administration of tartarised antimony, in emetic and afterwards in nauseant doses; repeated "swabbing"; opiates and inhalations of steam, not eren affording the amallest temporary relief. I therefore had recourse to the operation on the afternoon of the 30th, my patient displaying the same heroic firmness under the knife as on the former occasion. In its subsequent course, the present has 0 closely resembled the first attack, that it seems unnecesary to occupy space with the detrils. An equally successful result has not, however, been obtained. The use of the canula cannot jet be dispensed with, although within the last month the glottis has again become, in some degree, pervious to air; and on withdrawing the tube at my last visit (on the 7th inst.), and stopping the orifice in the trachea, I found that forced respiration could be maintained, with little inconvenience, for more than two minutes. The pulse was then 96, and the respiration (through the canula) 40. The signs of emphysema of portions of both lungs have of late been superadded to the auscultatory phenomena formerly noted. But the general health has undergone a considerable amendment, the patient being nor able to be out of bed during the day, and to occupy her time in reading, lnitting, and sewing. She eats with relish, and sleeps tolerably well without the aid of an opiate. The cod-liver oil is continued, in half-ounce doses, three times a day.

The great proclivity to laryngeal complication in pulmonary consumption is well known, the researches of Louis having long since established the fact that ulceration of this part of the respiratory apparatus, its usual seat being the junction of the vocal cords, or the cords themselves, cocurs once in every four cases.* I am disposed to regard the laryngitis in the preceding case as an unusual manifestation (owing probably to peculiarity of constitution) of the morbid action, in its early stage, from which these lesions result; this forming the predisposing cause in both attacks. Its increase, I believe, is denoted by the circumtance that, although the glottidean contraction has a cecond time been overcome, a structural impediment to the entrance of air by the glottis remains. From a state of complete occlusion, however, this orifice has of late been restored to a slight degree of patency; and, having seen the adventitious deposit in "scrofulous finger", and other localintions of the me diathesis, melt away under the influence of the wonder-working cod-liver oil, I do not despair of yet greater benefit being obtained in the present case from the continued employment of this invaluable agent.

Keith, July 1834.

\section{CASES OF PUERPERAL CONVULSIONS: WITH OBSERVATIONS.}

By A. B. STELLE, Esq.

Puerperal convulaions may be considered one of the gravest maladies met with in obstetric practice. The froquency of their occurrence, and the rate of mortality, as rocorded by authors, are sufficient to render the subject one of interest and anxiety to all who are engaged in midwifery practice. According to the tables of Dr. Fleetwood Churchill, founded upon the reports of thirteen practitioners, convulsions occur once in six hundred and nine cases. Individual experience, horever, raries considerably : thus, Dr. Granville, in six hundred and forty labours, met with only one case of convulsions; while Dr. Cusack had aix cases in three hundred and ninety-eight labours. The mortality is estimated by Dr. Churchill at about twenty-fire per cent.

I propose first to relate a few cases which have occurred in my own practice, and afterwards to make some remarks upon the nature and treatment of this formidable malady; a subject which appears open for discussion, as the most varied and conflicting opinions are found in the writings of obstetric authors.

CAsE I. Mrs. S., aged 21 Jears, a stout short-necked plethoric subject, of florid countenance, taking but little exercise, and eating heartily, had been subject to fits (said to be epileptic) when a child. In the last month of her first pregnancy, she observed that her feet and hands had lately swollen. For two or three days she complained of drowsiness in the day and restlessness at night; and on the 13th Sept. 1845, about noon, having remained in bed from feeling unwell, she was heard to fall heavily by her attendant, a female in the room below; who, on going upstairs, found her on the floor in a violent convulsive fit. She appeared to have fallen in the act of getting out of bed. About 4 P.x. on the same day, she was visited by my friend Mr. Walker, of Birkeuhead, who attended in consequence of my absence when sent for. This was the first occasion on which medical aid was sought, 80 that no preventive measures had been adopted. Mr. Walker took about sixteen ounces of blood from the arm, and administered castor-oil. On examination per vaginam, labour was found not to have commenced.

8 P.M. I saw the patient for the first time. Two fits had occurred since the bleeding, and one took place during $\mathrm{my}$ visit. The pulse was 120, full. The bowels had been freely relieved, and much undigested and irritating matter had been evacuated. The tongue had been severely bitten during the fits, which were very violent. In the intervals, stupor and stertorous breathing were present. No labour pains had been noticed. I took about twenty ounces of blood in a full stream, producing a decided effect on the pulse, applied a blister to the nape, gave five grains of calomel, and ordered two-grain doses to be repeated every hour.

Bept. 14th, 1 A.x. I saw her again. Two fits had occurred since my last visit, and one or two slight pains. She was partially conscious. On examination, the os uteri was found to be fully dilated, the membranes entire, and the head presenting. The fits were excessively violent, and appeared to threaten immediate death by asphyxia. During the paroxysms, the countenance was so horribly distorted, that none of the female attendants could be induced to stay at the bedside. Death seemed imminent: I never before or since witnessed such apparent-complete strangulation. Finding that free depletion and copious evacuation of the bowels, cold affusion and counter-irritation, produced no impression in lessening the severity of the fits, I determined to try the effect of emptying the uterus of its contents, and at once proceeded to deliver by version, which was easily done. The expulsion of the head was completed by the natural efforts, and was immediately followed by a very severe fit. The child (a female) was quite dead, but evidently recently so. The placenta was thrown off in $\&$ fow minutes, and the uterus contracted firmly. 
Th convulions now recurred with, if poseible, imareased violence at first, one about every quarter of an hour, and afterwards much more frequently; during the intervals, the patient was unconscious, and the breathing stertorous. the patient was une bandage from the arm, with the intertien of taking more blood, watching carefully the effect upon the circulation. After two or three ounces had escaped, upon the circulation. After two or three closed the orifice, and applied six leeches to the temples, and sinapisms to the calves of the logs. I may here notice that in the proress of the case the variable condition of the pulse was rery remarkable; sometimes it was full and soft, and at others scarcely to be felt.

12 A.x. Ten hours after delivery, Mr. Walker visited the anee with me; we found that the paroxysms had continued with grent violence, recurring five or six times in every bour; and during our visit a fit occurred, which we both expected would prove fatal. The pulse was 120; the breathing was free from stertor; nevertheless, the general aspect of the case was at this period so unfavourable, that we scarcely ventured to expect a farourable issue. The violence of the paroxysms was so great, that it seemed impossible that nature could hold out much longer. Howerer, on visiting the patient in the evening, I found her much better: the paroxysms had ceased since 12 o'clock, just twenty-four hours from the first seizure. She was partially conscious, and had slept a little. The lochia had appeared scantily. She was ordered to leave off all modicine, to take beef-tea and sago, and to have an enema of castor-oil and turpentine administered.

From this time the patient gradually improved. She was delirious for two or three nights, and once tried to get out of bed : this symptom was relieved by extract of henbane and morphia. She sat up on the twenty-third day. The lochia and milk were fully established. She had no recollection of her seizure, and remembered nothing in connexion with her illness previous to September 16 th. She suffered much inconvenience from the wound in her tongue, which was much aggravated by the action of mercury.

BEMARK8. In this instance the paroxysms far exceeded in violence anything I have witnessed before or since, and the case was altogether of a graver character than any that I have ever known to recover. I frequently quite expected the patient was about to expire from suffocation; and for several hours the means adopted appeared to have no control over the disease. Delivery, which is so strongly recommended by Dr. Robert Lee and others, failed to afford any relief to the symptoms; and it may hence be inferred that the eause of the convulsions does not invariably depead upon the irritation produced by the contents of the uterus, as some writers have supposed. It seems more reasonable to attribute the attack in the present case to an orerloaded state of the system, brought on by excessive eating and want of exercise during pregnancy.

The premonitory symptoms of swelling of the hands and feet are worthy of notice, as being in this case forerunners of very serious mischief, and therefore not to be overlooked when occurring towards the end of pregnancy; and the drowsiness in the day and the wakefulness at night would have been further indications of some disturbance in the nerrous system, had the patient been under notice previous to her seizure.

It is probable that no organic lesion existed; and that the stupor and stertorous breathing depended upon that state of the circulation which is described by Dr. M. Hall under the term "sphagiasmus laryngismus", in which the convulsive sction of the muscles of the neck prevents the free return of the blood through the veins, and thus induces congestion of the brain. There could have been but a very slight smount of effusion, if any, or those symptoms would carcely have disappenred 80 completely in 80 short a time. The delirium which supervened during convalescence was doubtless to be attributed to nerrous irritability, the result of debility from depletion, and it was at once relieved by on anodyne.

The successful issue of the case shows that the chances of reoviver are not elirairs to bo menored by the degree of everity of the paroryems, nor should owen very discouns: ing prespects make us despair. It may further be obeerved. that immediate reoults are not always to be expected ove from the most energetic measures; nor are we to conclude that they have been useless, although some hours mas elapee before we ean discover that any decided impression has been made. In this case there was no diminution in the violence or frequency of the fits until ten hours after delivery, when they at once entirely disappeared.

In the treatment of cases like the foregoing, the main indications are evidently free depletion and evacuation by purgatives; for, whatever opinions may be entertained as to the propriety of copious bleeding generally in puerperal convulsions, in such a type of the disease as 1 have endear roured to illustrate there can, I think, be little besitation in admitting the propriety of prompt and copious depletory measures to relieve at once the oppressed condition of the circulation and of the system generally. Of the question of delivery, I shall speak presently.

The administration of mercury, further than to act as purgative, is, I think, not called for, and I should not be disposed to adopt it in any future case; ptyalism, if produced, may, as in this instance, prove troublesome.

Ca8E Ir. A single woman, aged 19 years, in rery destitute circumstances, residing in a crowded unhealthy court. was taken in labour for the first time at 4 P.M. All went on well until eleven the next morning, when she was attacked with conrulsions, violent and frequent, but much less formidable in appearance than in the former case. She was bled to twenty ounces; and a dose of calomel was administered. After the bleeding, the fits ceased, and uterine action went on regularly for a few hours, when her friends gare her some ardent spirits, and the fits returned with great violence.

I first saw the case at 4 P.M., twenty-four hours after the commencement of labour. I found the head just abore the brim of the pelvis; the parts were all well dilated. I ap plied the long forceps, and delivered her of a large dead male child. One or two slight fits occurred after delivery, and she ultimately recovered, although convalescence was retarded from a want of proper nursing, and from the unfarourable condition of life she was in.

Remarks. This case differs from the last in its amenability to treatment. Here the removal of the contents of the uterus seemed at once to diminish the severity and frequency of the fits. Depletion to any large extent would not have been justifiable in this instance; but, no doubts the ore bleeding was of service. The convulsions were dependent rather upon irritability than upon an overloaded state of the system; and in patients of this class the disease not only requires obviously a less energetic use of the lancet, but often the entire omission of bloodletting; the main indication being to calm excitement and subdue irritability.

Case III. A prostitute, in the lying-in ward of the Liverpool workhouse, a stout heavy looking girl, was dolivered of a living male child (her first) on the 30th April at 4 A.M. The labour was natural, and not prolonged. An hour and a half after the birth she was seized with convulsions, which occurred at first every half hour, afterwards much oftener. She was quite unconscious in the intervals. The pulse was full; the scalp hot; the tongue furred; the breathing was stertorous; the uterus was strongly contracted. She was bled to about twenty ounces; cold affusion was applied to the scalp; a clyster of turpentine, assafœtida, and castor-oil, was administered; and ten grains of calomel were given by the mouth.

In the evening, the fits having occurred every half hous, she continued quite insensible. The pulse was incompressible; the pupils were dilated; the bowels had not acted, although two drops of croton oil had been given in addition to the calomel. The enema was repeated; five drops of croton-oil were also given by the mouth, and more blood was taken from the arm.

12 P.M. She was partially sensible, and could be roused 

setion was entabliched; bet the fits continued, and the pitiont sent.

No post mortem examination could be obteined.

Bunance. In patients of the sume class as the hat two, ivaleions are not very uncommon: they are to bo regarded w the result of mexbid irritability of the nervous system, inaced by irregular habits of life and a despondency of and, inseparable from their helpless and often hopeless condition. It is sometimes observed in large institutions for lying-in women, that several eases occur in succession, anibly from species of hysterical sympathy. These eres do not as a general rule require active depletion; pursatives, turpentine as an enema or by the mouth; and cold fuaion, being more appropriate; but in the instances shore related, the state of the pulse, and the condition of the vascalar gystem and that of the patients generally, coemed to warmant a certain amonnt of depletion.

CASE IV. An unmarried female, aged about 22 years, ene from a distant part of the country to be clandestinely confined of her illegitimate child. She was of low stature and short necked. The labour was natural and rather quick; it was unattended by any unfavourable symptoms. About an hour after delivery, I was hastily summoned, and learned that she had just had a fit, which, from the description, appeared to have had the ordinary characters of convulsion, but not very severe. She now felt rather drowsy and heary, but the fit had entirely left her. As a precautionary measure, the patient being of full habit, I took twelve ounces of blood from the arm, and gave an active purge; she had no return, but recovered favourably.

REMARKs. Here it is probable that an early recourse to the bncet prevented a more severe and protracted attack of convulsions, as the patient was one of those in whom we might fear the probability of their occurrence.

CAsE v. A poor woman, of very delicate health, and upare habit, had complained of illness during her pregnancy. She was delivered of twins; and soon after labour was completed, convulsions came on. When I saw her, she had had two or three fits. She was partially unconscious. I took twelve ounces of blood from the arm, and gave a purgative. She had two or three slight fits, and perfectly recovered.

Geyeral Remaris. In the treatment of puerperal convulsions, the highest authorities recommend copious depletion, almost without reservation. Dr. F. Churchill says:o The first thing to be done is to take away blood from the arm or temporal artery largely; if the paroxysms continue, this may be repeated." He insists on no condition as to the state of the patient, or as to the probable exciting cause of the fits, apparently considering that the existence per se of convulsions is a sufficient indication.

The experience of the late Mr. Crosse, of Norwich, was in favour of bloodletting. In his work on midwifery, he gives the history of twelve cases; in eleven of which free depletion was practised and followed by recovery. In the only fatal case, he says:- "In consultation, bleeding was not thought proper, and counter-irritation, etc., were the only means employed."

Dr. Copland, in his Dictionary of Medicine, in the article Puerperal Convulsions, observes:- "Depletion may be carried further in those states of the disease which assume the characters of eciampsia, or which are attended by great fulness about the head or stertorous breathing, than in Imost any other malady."

Dr. Rigby advises free depletion; and all the writers, with one exception (TJlex Smith), whose works I have consulted, recommend copious bloodletting as the first and gevent remeds; the extent to which it is to be carried, boing regalated mainly by the violence and froqueviog of

The history of the patient, her previous habite, a well as the peculiarities in each case in reference to the predispesing and exciting canses, are ignored altogether an indications for or against the use of the lancet; so that the practitioner is left without any guiding principles upon which to regulate his practice in this particular, and ho uses this powerful remedy almost entirely empirically. It is, nevertheleso, most important that some sound data should be given to regulate this very important and powerful remedy, for it is as injurious in unsuitable as it is indiepensable in suitable cases.

There is a somewhat similar difficulty with regard to what is perhaps the second matter in importance in the treatment of puerperal convulsions-namely, the question of interference in the progress of labour by artificial delivery; but here authorities are not all agreed as to tho main question; and few, if any, have pointed out any very satisfactory principles to guide us in deciding when it is necessary or proper to interfere, and when we ought to trust entirely to nature. Dr. Ramsbotham is in favour of turning; Dr. Collins is strongly opposed to it; and Dr. Churchill considers it a most hazardous measure. Dr. $R$. Lee deems it an essential part of the treatment to empty the uterus of its contents as speedily as possible. Dr. Rigby says there is little chance of the convulsions ceasing until delivery is completed. A later writer, however, has thrown much light upon this subject, and his observations appear to me highly valuable, and of the last importance in ro moring the difficulties above mentioned; I shall therefore quote his views, as stated in his recent work. The author I allude to, is Dr. Tyler Smith, whose views are founded upon Dr. Marshall Hall's researches into the physiology of the nervous system; and his practical application of that physiologist's discoveries to the pathology and treatment of puerperal convulsion is interesting and useful.

Dr. Tyler Smith considers that puerperal convulsions depend upon one of two cruses-viz., irritation of the spinal marrow, or upon some irritation of excitor spinal nerves; and then he goes on to say:- "The action of bloodletting on the spinal marrow is greatly modified by the condition of the circulation; in fulness of the vascular system, it is the most powerful scdative of spinal action we possess; hence, venesection is the grand remedy in the simple form of puerperal convulsions, where the disease chiefly depende upon stimulation of the spinal marrow by excess of blood, or on the mechanical pressure exerted by the blood on that organ, together with the counter-pressure of the distended brain on the medulla oblongata. But another most important intention of bloodletting is that of preserving the brain from injury during the convulsion. Besides the primary cerebral congestion, which may have been the cause of the attack by its counter-pressure on the medulla oblongata,
the convulsive action itself with the glottis closed, the various sphincteric actions in operation which constitute what is called by Dr. M. Hall sphagiasmus laryngismus, cause the greatest turgidity of the ressels of the head, and are dangerous sources of fatal cerebral congestion, or of serous or sanguineous effusion; thus, in plethoric states of the circulation, bloodletting is curative in its action on the spinal marrow, preventive in its action on the brain.

"In the absence of definite ideas regarding the effect of bloodletting in this malady, it has often been pushed to excess, or practised where it should have been altogether avoided. In the numerous cases where, besides vascular excitement of the spinal marrow, some irritation of the spinal excitor nerves exists as a conjoined cause of convulsions, repeated bleedings will often fiail to subdue the disease, unless the eccentric irritation be at the same time removed; when irritation of the utcrus, rectum, or the stomach, is in part excitor of the convulsiun, bleeding alone cannot bo relied on. It may at first diminish the impressibility of the central organ, rendering it less sensible of the incident irritation; but if persisted in to a large extent without the removal of the eccentric irritation, it becomes in the end 
menivels thiurious, by increasing instead of diminishing the excitability of the opinal marrow."

He then furnishes the rule by which we are to be guided. WThe propriety and the extent of bloodletting must be entimated not by the violence of the disense, but by the the of the circulation in the interval of the fits, and with enecial reference to the different effects of vascular plethor and vacuity upon the spinal centre."

These obcervations of Dr. Tyler Smith will, I think, render the practitioner valuable aid in coming to a decision upon the question of depletion in the treatment of this discase, and especially in reference to the repetition of bloodletting when the first quantity taken, although large, has failed to relieve the fits. I apprehend that, in most cases of puerperal convulsions of a severe character, one full bleeding would be justifiable and proper, on the principles laid down by Dr. T. Smith; and when this has been done, and the fits still continue urabated, before pushing depletion further, bearing in mind the principles he has enunciated, we are led to investigate the various possible sources of irritation to incident excitor nerves, such as distension of the uterus or of the bladder, or the presence of irritating mattars in the stomach or intestines, and the propriety of the administration of opiates, especially by the rectum, would demand a full consideration.

In considering the propriety of interference in the progress of labour-a question upon which, as we have before noticed, the authorities are not at all agreed-We derive equal assistance from the views of Dr. Tyler Smith. After observing that the question of interference is one for which no arbitrary rule can be laid down, but which must be decided in each individual case by the particular circumstances, due regard being paid to the excitability of the uterus under the stimulus of the fotus, and under the artificial interference, he advises the evacuation of the liquor amnii, which, by relieving the distension, diminishes the size of the organ and the quantity of blood circulating through it; and hence, although it renders the uterus more sctive by bringing its parietes into contact with the fotus, it renders the organ itself less irritating to the general apinal system. The evacuation of the liquor amnii is to the uterus what the partial action of an emetic or an coma is to the stomach and intestines. With regard to the general principle which should guide us in deciding upon artificial delivery, it is to be observed that, whenever it can be effected with less irritation than would be produced by the continuance of the child in the parturient canal, and its expulsion by the natural process, it is advisable that it should be performed.

These general principles appear to be applicable to all ordinary cases of puerperal convulsions, and will be found of material assistance in enabling us to treat that formidable disease, if not with invariable success, at least upon rational and scientific principles; and they will also serve in some measure to reconcile the apparently contradictory and diversified statements and theories of different and differing authors.

It does not fall within the object and limits of this paper to speat of the numerous other special remedies which have been recommended in the treatment of puerperal convulsions, my intention being to draw attention to the two main questions of blood-letting and artificial delivery; nevertheless, I do not wish to leave the subject without some allusion to the use of chloroform. I have no experience of its effects in this disease in my own practice, but have had considerable opportunities of noticing the phemomens attending its administration in surgical cases; and, from observation and reasoning, I should not be led to expect much benefit from it, bejond the collateral adrantage of allaying nervous excitement in some exceptional cases. I ay exceptional cases, because I believe that, in the most common form of this disease, in which there is more or less congestion of the brain, and where the fits are produced by other causes than those which depend upon excitement from without, or upon any impression made upon the sentient faculties, such as fright, excessive pain or irritation trom prolonged sufering, or the lite; chlocoform covld not be expected to exert any influence over the origin of the disense. It might, on the contrary, set as a predispocing cause, and render the paroxyams more frequent and vio lent: for it has been noticed by Dr. Marahall Hall, that, when the functions of the true cerebral or sentient portion of the nerrous system are diminished or abolished, as is the case in ansesthesia, the irritability of the excito-motory ar true spinal system of nerves is increased. Hence it follows, that convulsions being a disease of the true spinal system, they would be the more readily produced, the spinal nerres being more susceptible of any morbid impression convejed to them; so that the only probable advantage to be derived from the use of chloroform is to shut out any exciting causes of convulsions which act through the medium of the functions of sensation; and this, be it remembered, is at the risk of rendering the system more susceptible of those much more important exciting causes which are probably, in almost. every case, the real origin of the disease. That chloroform does not directly control the functions of the excitomotory system, is manifest enough from its ordinary effect upon the progress of natural labour; for there, although sensation is more or less diminished or annihilated, yet the contractions of the uterus, an excito-motory act, still continue.

It is further worthy of remark that chloroform frequently produces a state of system nearly approaching, if not actually reaching that of convulsion; and I have frequently observed that it produced a considerable amount of congestion of the vessels of the head and neck-in fact a slight. degree of sphagiasmus - a condition which cannot be looked upon as favourable to the patient, already nearly asphyxiated by the paroxysms.

Another objection might be urged against the use of chloroform in many cases of puerperal convulsions; namely, the peculiar condition of the circulation which, as noticed by myself and by other observers, frequently obtains in this disease. The heart's action fluctuates in a most remarkable manner, the pulse sometimes being full and indicating a fair amount of vascular force; at others, $80 \mathrm{small}$ and feeble as scarcely to be felt. Now, if chloroform should be given too a patient in the state indicated by the latter condition of the pulse, it might be regarded as a most fortunate escape if the heart's action were not altogether abolished, as we have seen in some unfortunate cases which have occurred in surgical practice, where a very small quantity of the anesthetic agent has destroyed life by paralysing the action of the heart, already enfeebled by the supervention of depressing causes, such as fear or the like.

In cases where there exists, as a prevailing peculiarity, a great amount of nervous excitability of the system accompanied by restlessness, chloroform may be useful by producing sleep; or, in cases where pain seems to be the exciting. cause, anrsthesia would no doubt be a useful means of relieving the patient; and to these and to analogous formo of the disease I believe its use should be limited.

In the sthenic forms of convulsions, accompanied by congestion and fulness of the vascular system, it can, I think, do little good, and might do much mischief.

Iirerpool, July 1854.<smiles>CCCC1CC1</smiles>

CLINICAL NOTES ON CHOLERA.

By W. LAUDER LINDSAY, M.D., late Resident Physician to the Surgeon Square Cholera Hospital, Edinburgh.

$$
\begin{aligned}
& \text { [Continued from pape 3s1.] } \\
& \text { PEIOTED CHOLERA. }
\end{aligned}
$$

Ors good instance of this rare form of malingering came under my notice, and I think merits being recorded, both on account of the audacity of the attempted imposition, and of the rather unusual but highly efficient nature of the treatment. In large general hospitals, it is by no meano uncommon-nay, it is sometimes a matter of every day experience-to meet with parsons who sesume or faigh 